Published online: June 30, 2006

\title{
Pseudoaneurysm of the Splenic Artery
}

\author{
Steffen Rickes Klaus Mönkemüller Marino Venerito Peter Malfertheiner \\ Department of Gastroenterology, Hepatology and Infectious Diseases, Otto von Guericke University, \\ Magdeburg, Germany
}

A woman, aged 63 years, was admitted to the hospital with upper abdominal pain. She had been previously diagnosed with alcoholic chronic pancreatitis and was known to have pancreatic pseudocysts. Initial evaluation revealed a rapid pulse and a low blood pressure with a hemoglobin of $7.9 \mathrm{~g} / \mathrm{l}$. Conventional ultrasound showed two large pseudocysts with echogenic material (fig. 1). With color Doppler sonography blood flow within one of the pseudocysts was found (fig. 2). With pulsed-wave Doppler sonography an arterial spectrum within the pseudocyst could be detected (fig. 3). A pseudoaneurysm of the splenic artery was suspected. The diagnosis was

Fig. 1. Conventional ultrasound showing two large pseudocysts with echogenic material.

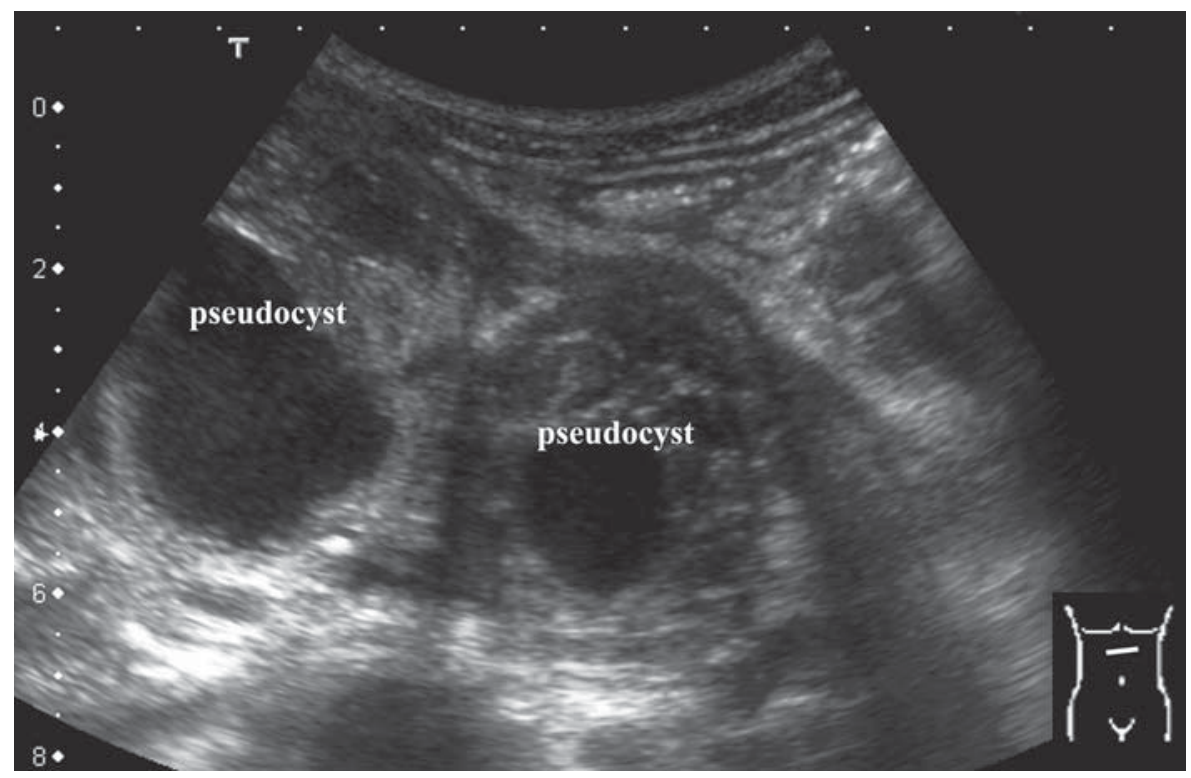

\section{KARGER}

Fax +4161306 1234 E-Mail karger@karger.ch www.karger.com
PD Dr. Steffen Rickes, Otto von Guericke University Magdeburg Department of Gastroenterology, Hepatology and Infectious Diseases Leipziger Strasse 44, DE-39120 Magdeburg (Germany)

Tel. +493916713100, Fax +49 3916713105

E-Mail steffen.rickes@medizin.uni-magdeburg.de 
Fig. 2. With color Doppler sonography blood flow within one of the pseudocysts was found.
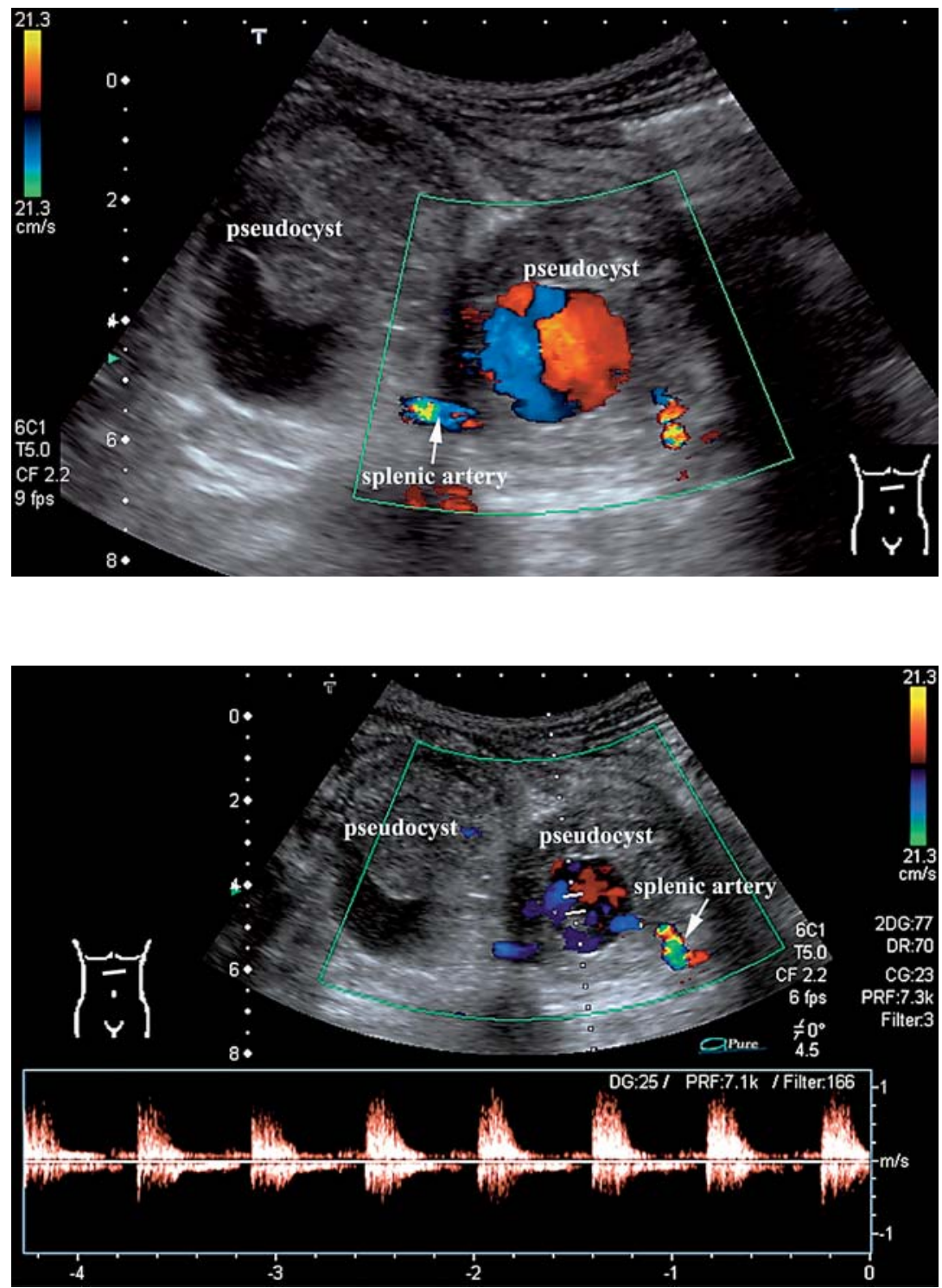

Fig. 3. With pulsed-wave Doppler sonography an arterial spectrum within the pseudocyst could be detected. A pseudoaneurysm of the splenic artery was suspected.

confirmed by angiography (fig. 4). Bleeding was successfully treated with the deployment of metallic coils into the splenic artery.

One of the complications of pancreatic pseudocysts is that of significant bleeding. Bleeding may occur into the pseudocyst or may occur when the cyst ruptures into the gastrointestinal tract or into the peritoneal cavity. When bleeding occurs into the pseudocyst, the cyst may enlarge causing abdominal pain and pressure effects or blood may pass through the main pancreatic duct into the duodenum. The latter appears to be rare and is sometimes called hemosuccus pancreaticus [1]. An additional issue is whether bleeding is caused by erosion of a vessel wall or because of rupture of a pseudoaneurysm. The splenic artery appears to be the most common artery involved in pancreatitis-associated inflammation with major bleeding but bleeding may occur from other vessels including the gastroduodenal artery, gastric artery and hepatic ar- 


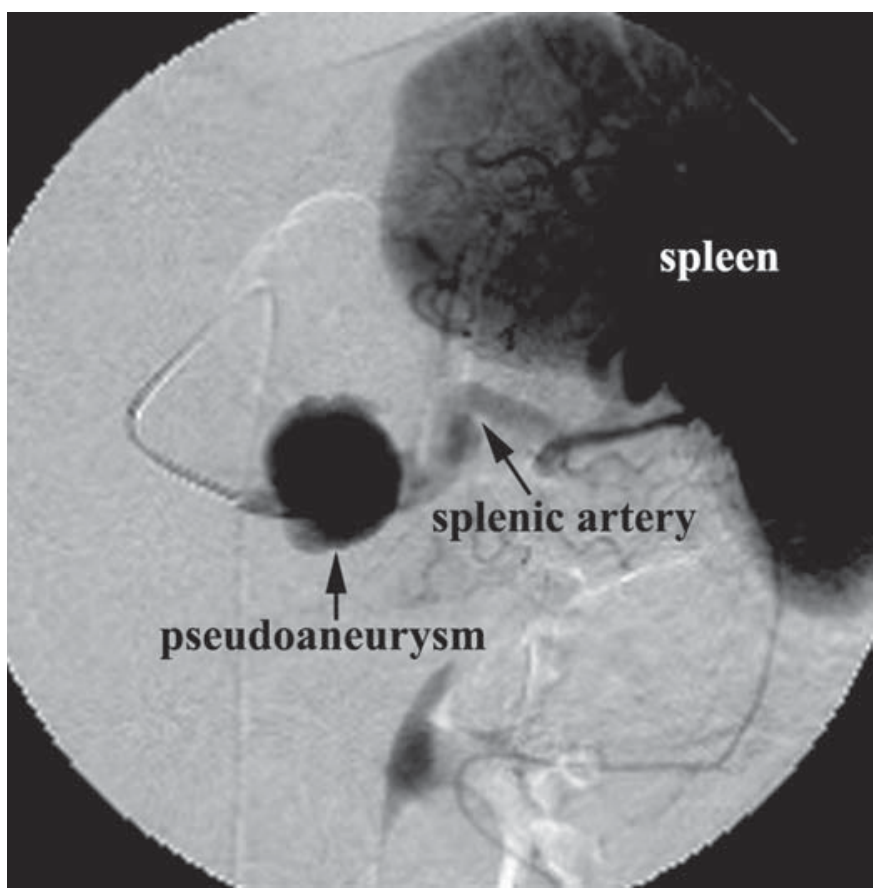

tery. True aneurysms of the visceral arteries are found in only $0.2 \%$ of the general population [2]. In these aneurysms, those of the splenic artery account for more than $50 \%$ [2]. The causes of visceral aneurysms include atherosclerosis, medial degeneration, infection, fibromuscular dysplasia, and congenital anomalies [2, 3].

Helpful diagnostic information for patients with pseudoaneurysms of the visceral arteries can be obtained by Doppler ultrasound and contrast-enhanced CT scans but most patients will proceed to angiography [4-6]. Whether patients are best managed by angiographic occlusion of blood vessels or by surgery needs to be determined for each individual patient based on the results of investigations and clinical features.

Fig. 4. The diagnosis of a pseudoaneurysm was confirmed by angiography.

\section{References}

1 Rickes S, Kolfenbach S, Kahl S, Malfertheiner P: Gastrointestinal bleeding and pancreatic pseudocysts. J Gastroenterol Hepatol 2004;19: 711.

2 Rogers DM, Thompson JE, Garrett WV, Talkington CM, Patman RD: Mesenteric vascular problems. A 26-year experience. Ann Surg 1982;195:554-565.
3 Rickes S, Wermke W: Aneurysm of the superior mesenteric artery - be careful with the diagnosis of a pancreatic tumor. Med Klin 2003. 98:458-460.

4 Dorffel T, Wruck T, Ruckert RI, Romaniuk P Dorffel Q, Wermke W: Vascular complications in acute pancreatitis assessed by color duplex ultrasonography. Pancreas 2000;21:126-133.
5 Ishida H, Konno K, Komatsuda T, Sato M, Naganuma H, Hamashima Y, Ishida J: Gastrointestinal bleeding due to ruptured pseudoaneurysm in patients with pancreatitis. Abdom Imaging 1999;24:418-421.

6 Mortele KJ, Mergo PJ, Taylor HM, Wiesner W, Cantisani V, Ernst MD, Kalantari BN, Ros PR: Peripancreatic vascular abnormalities complicating acute pancreatitis: contrast-enhanced helical CT findings. Eur J Radiol 2004; 52:67-72. 